\title{
Quantitative Analysis Method of College English Curriculum Based on Blended Teaching
}

\author{
Liang Cao ${ }^{1}$, Gefei Dong ${ }^{2 *}$ \\ ${ }^{I}$ Foreign Language Teaching and Research Department, Yingkou Institute of Technology, Yingkou, \\ Liaoning, China \\ ${ }^{2}$ Foreign Studies College, Northeastern University, Shenyang, Liaoning, China \\ *Corresponding Author.
}

\begin{abstract}
The development of industry is inseparable from the improvement of technical personnel's English level. Nowadays, College English classroom is inefficient. Various experts and scholars start from changing the teaching content, teaching methods and teachers' position in the classroom to solve the practical problems. No matter what aspect of the reform has promoted the further development of College English teaching, but it has not completely solved the practical problems in College English classroom. This paper proposes a quantitative teaching model of College English classroom performance to stimulate students' enthusiasm. Through the combination of qualitative analysis and quantitative analysis, this paper analyzes the teaching practice results of College English curriculum integration. The research shows that the integration of College English curriculum and multi teaching education can effectively improve students' English literacy. In the current environment, it is an effective way for colleges and universities to carry out media literacy education. The study also reflects the low level of students' English literacy, which needs to be paid attention to.
\end{abstract}

Keywords: Industry, College English, blended teaching, quantitative analysis.

\section{Introduction}

A series of teaching reforms have been carried out in full swing. Flipped classroom and network teaching methods have emerged. Their purpose is to make English teaching achieve better results. Nowadays, there are some problems that can not be ignored in College English classroom [1-2]. Experts and scholars start from changing the teaching content, teaching methods and teachers' position in the classroom to solve the practical problems. No matter what aspect of the reform has promoted the further development of College English teaching, but it has not completely solved the practical problems in College English classroom. Most students are not very active in learning English. Few students actively interact and cooperate with teachers in class; The classroom atmosphere is dull; After a class, it is a kind of torment for both teachers and students. Teachers don't get a sense of achievement, and students don't feel a sense of harvest [3].

The main reason why flipped classroom and online courses fail to fundamentally solve the dilemma of College English teaching is that they can not fundamentally establish a reasonable relationship between teaching and learning in College English teaching. Many education experts have said that both flipped classroom and online teaching are means, which play an auxiliary role and can not replace the role of teachers in teaching. Therefore, an effective teaching mode that can play a role in the traditional classroom is the top priority of College English teaching reform. A good teaching mode can establish a reasonable relationship between teaching and learning, that is, the mutual need between teaching and learning [4-6]. Teachers need to teach, teach what they have learned well, and students need to learn, because they can apply what they have learned.

ISSN: 0010-8189 


\section{Learner differences and teacher differences}

\section{(1) Intelligence factor}

When we investigate the characteristics of learners, we should first consider the intelligence factors of learners. Intelligence factor refers to the tendency point of talent ability. According to Gardner's theory of multiple intelligences, a person will only show special "talent" in one or several intelligence factors. Hao Mei et al. (2010) conducted an empirical study on learners' psychological factors that affect English performance, and confirmed that there is a significant positive correlation between multiple intelligences and learners' learning efficiency. To a certain extent, it provides a basis for educators to set up courses and divide learners. Learners with higher language intelligence will be relatively easier to master the language, whether it is the mother tongue or the second language. Accordingly, learners with higher musical intelligence may be easier to learn phonetics and oral expression. The communication ability of learners with higher interpersonal intelligence will help them to use the second language more easily for interpersonal communication, effectively carry out the interaction between teachers and students in the classroom, and complete the learning task [7]. However, how to consider the weight of each of these multiple intelligences, and whether the learners who embody similar intelligence factors should be divided together, or the complementary deployment, still need more empirical research to prove.

\section{(2) Non intelligence factors}

Non intelligence factors include all psychological factors except memory, attention, observation, imagination and thinking. From the perspective of learners, it includes learning motivation, learning style, learning strategy, language foundation, interest, will and so on. Non intellectual factors integrate more learners' personal characteristics of autonomous consciousness, some of which are constantly changing with the change of learners' knowledge structure, the maturity of thinking and the change of social role orientation. For example, from the perspective of learning motivation, some learners are aiming to pass the exam, some learners are preparing for studying abroad in the future, and some learners are preparing for their future work in a certain field. In terms of learning style, for example, some learners tend to cooperate in learning, and they are more likely to complete cooperative tasks in task-based teaching mode; However, some learners are more inclined to study independently. They are not suitable for task-based teaching that requires cooperation with others, and prefer to complete tasks such as writing or personal reports independently [8]. Because of their controllability and changeability, these non intelligence factors can be improved and adjusted through the conscious training of teachers on the one hand, and can also be changed through the efforts of learners themselves on the other hand. This kind of change can help learners to master the language more easily and improve their language use ability. In terms of curriculum setting and learner division, we can also try to organize learners with similar non intelligence factors to provide more suitable curriculum content, teaching strategies and teaching resources for specific groups of learners.

\section{(3) Personality characteristics}

In the study of the relationship between learners' personality and learning efficacy, most scholars focus on the two simple personality characteristics of Learners: introversion and extroversion. Empirical studies have confirmed that there are differences in the energy efficiency of the five different dimensions of English learning between extroverts and introverts. But in fact, the personality of learners can not be simply divided into introversion or extroversion. First, introversion or extroversion are not two simple and isolated personality traits. Most people are in the middle of these two extremes and tend to be extroverted or introverted; Second, there is a more detailed division of personality characteristics, such as independence and dependence, cowardice and boldness; For example, Fromm divides personality into five types: acceptance type, conquest type, hoarding type, market type and creation type; At present, the cartel 16 Personality Factor Questionnaire (16PF), which is widely used in personality assessment, analyzes 16 personality factors and so on. The detailed analysis of learners' personality and the relationship between different personality characteristics and learning effectiveness are lack of more in-depth 
research. There is no clear attempt in the curriculum and the practical operation of dividing students with similar personality into classes.

\section{(4) Learner commonality}

Under the condition of limited teaching resources, College English teaching can not achieve complete personalized teaching. Therefore, after discussing the differences of the above three aspects of learners, we still need to return to the integration of learners' commonness. In terms of resource use and learner division, should students with similar learning ability, personality characteristics and psychological factors be classified into one category by emphasizing their commonness, or should they consider the complementary and selective matching of various factors, and how to make the individuality obey commonness and highlight individuality in commonness, What is the degree of personality difference to distinguish two or two different types of learners, how to evaluate the weight of each component of learner difference, and how to form an effective measurement system, all these problems need to be deeply studied and discussed by educators.

\section{(5) Teacher differences}

Teaching and learning is an interactive process. In addition to fundamentally depending on the learners themselves, teachers, as an important part of the teaching process, also play a crucial role in learners' learning efficiency. As a humanized individual, teachers also reflect the differences in intelligence, emotion, style, interest and personality. In terms of teacher-student ratio, teachers' individual differences should also be taken into consideration, such as the compatibility between teachers and students, the similarity of teachers and students' personality characteristics, etc. At present, the course selection system in many colleges and universities, on the one hand, reflects the "student-centered", respects the individual will of students, but at the same time, it also has a certain blindness, and ignores the important role of teachers as organizers and guides of teaching practice [9-10]. In practice, students can not simply choose teachers, but should provide students with certain guidance and suggestions to help students make a scientific and reasonable choice on the premise of knowing themselves and teachers, and this choice should be in line with the adaptability and compatibility of students and teachers as far as possible.

\section{The teaching mode of quantifying College English classroom performance}

The theoretical basis of "learning motivation" was put forward for the first time in "teaching theory" co authored by M.A. Danilov and B. yexipov, experts of Soviet teaching theory. Based on the theory of learning motivation, this paper studies the teaching mode by using the driving effect of scores. College English classroom should start from the mutual needs of teaching and learning to reform the teaching mode, with the driving force of learning as the basic theoretical basis. English is different from other subjects, English learning lies in more listening and more practice, in the classroom can not better guide students to listen, read, write and translate the practice can not achieve good teaching effect, so the English classroom can not be the situation of the teacher alone, but should get the active participation of students. Teachers can enhance students' learning motivation by scoring their acquired knowledge. Combined with this theory, the two teaching classes I taught started to implement the teaching mode of individual performance quantification and group performance quantification two years ago, so as to make students have the motivation to learn English in English class, participate in English class purposefully, and make college English classroom atmosphere lively and teaching effect good. At the same time, through the combination of individual performance quantification and group performance quantification, we can change the monotonous group performance centered teaching mode, which can evaluate students more objectively, achieve the principle of fairness and justice, do not mix with any personal feelings of teachers, so that every point students get has a source, and it is also conducive to deal with the relationship between teachers and students.

(1) To stimulate the enthusiasm of students with usual performance scores

ISSN: 0010-8189 
Students' performance in English class will be presented with specific scores. The reform of English classroom teaching mode, according to the demand relationship between teaching and learning, according to the theory of learning motivation which has been studied for many years in the education field, make clear the specific status and role of teachers and students in English classroom, show their abilities and do what they need. Set up some fixed classroom teaching activities in the classroom to stimulate students' motivation and enthusiasm in English learning. Some students who take the initiative to speak and answer questions in class and participate in teaching activities are given certain scores. At the end of the term, these scores are calculated into the usual score part of the final score according to a certain proportion. In this way, the situation of students' passive participation in teaching activities in class can be reformed by taking scores as the driving force, In order to stimulate students' enthusiasm in learning English, we should combine short-term driving force with long-term driving force. Through the quantitative model of students' usual performance, that is, using specific scores to evaluate students' usual performance, we can improve students' enthusiasm in English class, make the English classroom atmosphere active, change the situation of teachers singing monologue in class, make teachers and students achieve better interaction, give full play to the role of English class, and make teachers achieve the best teaching effect, Students get the most benefits.

\section{(2) Using rich and colorful teaching activities as the carrier of usual performance points}

In order to ensure the good implementation of individual performance and group performance quantification, the most basic and most difficult thing is whether we can arrange the teaching links that attract students and the reasonable distribution of each link's score. To solve this problem reasonably is the key to ensure the smooth implementation of this teaching mode and achieve the best effect. English teachers should set up different teaching activities according to different teaching contents, so that students can participate in them, and determine the score of each part according to the link or difficulty of teaching activities, so that students who participate in the activities can get corresponding scores according to their performance in the activities, so as to achieve fairness and justice. In order to implement the teaching activities effectively, it is necessary to ensure the balanced strength of the group members when the students are grouped. The students with good foundation should be evenly distributed in each group, play the role of leading other members to participate in the activities, make them become the organizers and leaders of the group, and coordinate the internal relations of the group members. In this way, there will be no phenomenon that the score of a group is too high or too low due to the imbalance of strength, and the enthusiasm of each group will not be affected because of the score difference. Traditional CDIO architecture model is shown in Figure 1. CDIO is conception, design, implementation and operation. The emergence of CDIO is mainly to cultivate the students to have their own ideas in conception and to have distinct innovation in design. Finally, it can automatically develop and operate the results, and turn the idea into reality. As the online English learning platform is a typical multi-user system based on the Internet, the micro-service architecture is adopted in the system architecture model (Figure 2).

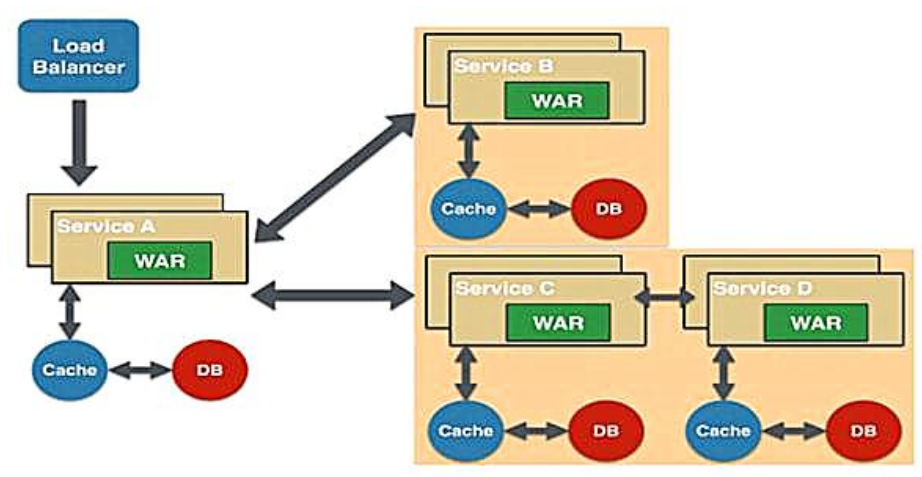

Figure 1 Traditional monomer architecture model 


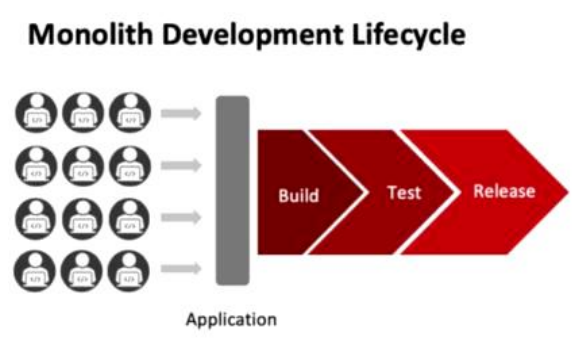

Figure 2 Microservice architecture module

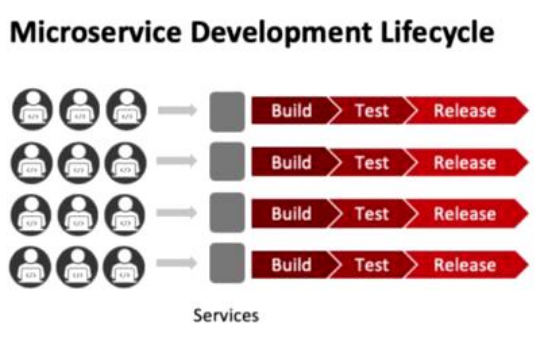

(3) The concrete implementation of usual performance weight

Starting from the entrance of freshmen, it is implemented in the teaching class. Set up the scoring links of individuals and groups in teaching activities. First of all, Grade A, B and C tests should be conducted for freshmen to make sure that there is not much difference in the level of students in each teaching class. Secondly, translation and oral test should be conducted in the teaching class. According to the results of translation and oral test, the students should be divided into groups within the class. Grouping should ensure that the strength of each group member is balanced, and the students with good oral English drive the students with poor oral English. Thirdly, according to the rules of the implementation of the classroom scoring link.

Finally, the sum of the individual performance score and the group performance score is multiplied by the corresponding percentage of the usual performance score in the final score to get the final student's usual performance score. Grouping in the class should be based on the oral English and translation scores of all the students in the class, as well as the wishes of the students themselves. A group should be formed according to the principle of combining good English foundation with poor English foundation. The scoring process should be based on the principle of combining before and after class to avoid the phenomenon that a student scores too high or too low due to objective reasons. Therefore, in the process of implementation, the upper limit of the number of scores and the number of scores will be set. To control a classmate's high score. Set up some recitation after class, preview homework to adjust the situation that students have no chance to get the usual performance points in class. The establishment of scoring links in class can stimulate students' interest in active participation in class. The personal part of the scoring process in class is divided into three parts: reading, translation and exercises; Group scoring is divided into two parts: Group homework and group performance, which need to be combined with preparation after class and play in class.

\section{The teaching mode of quantifying College English classroom performance}

From different perspectives, the concept and connotation of content semantic analysis have different representation forms, as shown in Table 1. Content analysis method originated from the study of communication. Its main principle is to analyze the information contained in the content of literature and its changes, so as to reproduce and infer the content of literature. In the field of psychology, Osgood, a famous American psychologist, proposed semantic analysis to measure the different meanings of the same concept for different people [10]. A typical semantic difference scale establishes seven grades between "good" and "bad". Usually, "0" stands for "neutral", "1" stands for "little", and "3" stands for "extreme". Semantic analysis is mainly used for theoretical testing, measurement of individual understanding, attitude and motivation, and diagnosis of individuals.

ISSN: 0010-8189 
Table 1 The concept of content semantic analysis

\begin{tabular}{|l|l|l|l|}
\hline Visual angle & Name & Concept \\
\hline Psychology & $\begin{array}{l}\text { Semantic } \\
\text { analysis }\end{array}$ & $\begin{array}{l}\text { It is a method to study the meaning of things by using the semantic region } \\
\text { subscale. The subjects are required to evaluate a thing or concept on several } \\
\text { semantic scales with grades, so as to understand the meaning and strength of the } \\
\text { thing or concept in each dimension }\end{array}$ \\
\hline \multirow{2}{*}{ Education } & $\begin{array}{l}\text { Content } \\
\text { analysis }\end{array}$ & $\begin{array}{l}\text { Practical content } \\
\text { analysis }\end{array}$ & $\begin{array}{l}\text { Statistical analysis of some subject words or specific } \\
\text { vocabulary, and give the weight of Xiaotong (such as different } \\
\text { fonts, layout location, ranking order, etc.) to infer the original } \\
\text { prisoners and possible consequences }\end{array}$ \\
\cline { 2 - 4 } & content analysis & $\begin{array}{l}\text { Semantic content analysis is analyzed from the semantic level } \\
\text { of content, which can be further divided into designation } \\
\text { analysis, attribution analysis, assertion analysis and so on }\end{array}$ \\
\cline { 2 - 4 } & & $\begin{array}{l}\text { Analysis } \\
\text { symbolic media }\end{array}$ & $\begin{array}{l}\text { It only counts the frequency of specific symbols (such as some } \\
\text { subject words) from the literal, does not consider the } \\
\text { semantics, and does not introduce the weight, so as to analyze } \\
\text { the content }\end{array}$ \\
\hline \multirow{2}{*}{ Computer } & $\begin{array}{l}\text { Semantic } \\
\text { analysis } \\
\text { method }\end{array}$ & $\begin{array}{l}\text { Semantic analysis a complex process, involving linguistic research, text } \\
\text { similarity calculation, ontology construction, ontology reasoning and so on }\end{array}$ \\
\hline
\end{tabular}

The research group takes the 2013 high-quality class video "Weisi" of the central audio visual education Museum as an example, and divides the teaching of this class into five main links, which are: (1) case introduction, generalization and definition. The teacher uses multimedia courseware ppt and Geometer's Sketchpad for demonstration, and the time is 5 minutes and 18 seconds. (2) The main activity is to demonstrate with PPT and Geometer's Sketchpad. The time is 4 minutes and 38 seconds. (3) The main activity is the dialogue between teachers and students around the multimedia demonstration, which takes 1 minute and 56 seconds. (4) The main activity is the dialogue between teachers and students around the multimedia demonstration, the time is 2 minutes and 26 seconds; (5) summarize knowledge, sublimate new knowledge, the classroom activity is the dialogue between teachers and students around the multimedia demonstration. Learning activities are recorded according to Table 2 below.

Table 2 Learning activity log

\begin{tabular}{|c|c|c|c|c|}
\hline Number & Field & Data type & Meaning & Remarks \\
\hline 1 & Record number & Integer & & \\
\hline 2 & User number & Integer & & \\
\hline 3 & start time & Time & & \\
\hline 4 & End time & Time & & \\
\hline 5 & Resource number & Integer & $\begin{array}{l}\text { Learning content } \\
\text { number }\end{array}$ & $\begin{array}{l}\text { New records are generated when } \\
\text { learning content changes }\end{array}$ \\
\hline 6 & Accompanied by parents & Small integer & & \\
\hline
\end{tabular}


By using the S-T analysis function of digital classroom analysis tool, this paper analyzes the classroom, and finds that in different links of classroom teaching, the teaching mode presents different characteristics, among which the first, third and fifth links are lecturing teaching mode, which is characterized by teachers' lecturing behavior. In the interaction between teachers and students, teachers are the main body and students are the receptors. The second link is the dialogue teaching mode, which is characterized by more interaction between teachers and students, high interaction density, and more students' interaction and exploration; the fourth link is the mixed teaching mode, which is characterized by teachers' guidance, checking students' mastery of knowledge in the way of practice, and teachers and students are the main body of interaction. Finally, the S-T analysis of the whole class shows that the teaching mode of this class is mainly teacher teaching.

For the teaching analysis of digital classroom, we can use the education big data research method to make statistical analysis on the research variables. For example, through the statistical analysis of similar classroom teaching models shown in Figure 3, we find the basic characteristics of different disciplines; the significant characteristics of new teachers and experienced teachers in terms of teacher-student interaction, behavior change rate, theme coverage rate, etc. In addition, large-scale statistical analysis of classroom real-time response can be carried out by using big data analysis. It is found that the normal relationship between non response time and response time is between 2 and 3 .
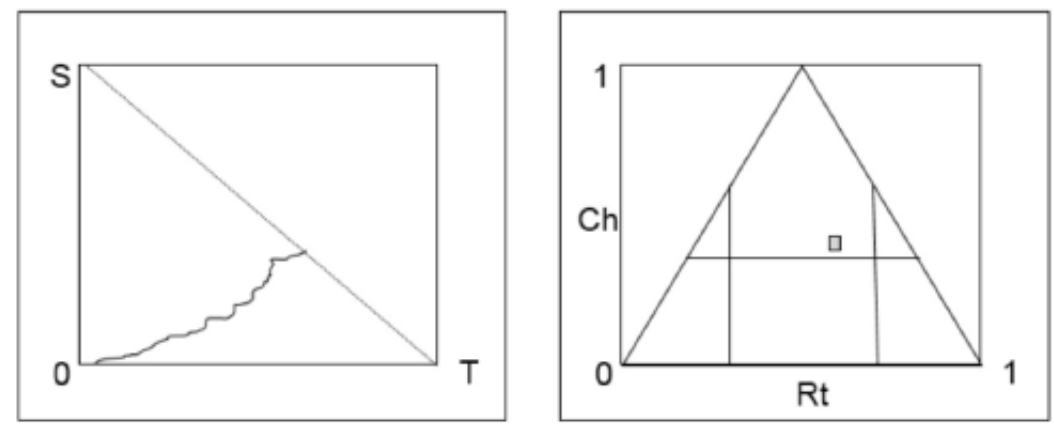

Figure $3 \mathrm{~S}$-T analysis chart of the second link in the classroom teaching of "Wei $\mathrm{Si}$ "

\section{Conclusion}

It is an effective way to stimulate students' enthusiasm in learning English by quantifying their usual performance scores in College English classes. This method makes use of the incentive effect of scores, so that every student in the class can pay attention to their usual performance. Teaching and learning is a mutually beneficial relationship, teachers teach well is the premise, but also with the cooperation of students and serious study. A lively and lively atmosphere in College English class is essential to improve college students' overall English level. And college students pay more attention to their scores, using scores to drive their enthusiasm in class is an effective method. Only by reasonably arranging the classroom activities with corresponding scores and making students get an objective evaluation after their own efforts, can they fully stimulate the enthusiasm of students in learning English, and also enable them to apply the knowledge they have learned to the activities of English classroom so as to achieve learning for use and improve their English application ability.

\section{Acknowledgements}

This research was supported by The Social Science Fund of Liaoning Province (Grant No. L18BYY010).

\section{References}

[1] Zhou Yuanqing. the Construction of Excellent Course Materials is an Important Measure of Teaching 
Reform and Innovation. China Higher Education Research, 2003 (1): 12-12

[2] Li Zhiyi, Zhu Hong, Liu Zhijun. Guiding the Teaching Reform of Higher Engineering Education with the Concept of Achievement Oriented Education. Higher Engineering Education Research, 2019, 000 (002): 29-34

[3] Wang Zongping, Zhuang Huihua. Emphasizing Fitness and Neglecting Competition -- Reform and Practice of College Physical Education. Sports Science, 2001, 021 (001): 22-25

[4] Liang Dingfang. My View on Foreign Language Teaching Reform. Foreign Language Teaching Theory and Practice, 2001 (1): 8-11

[5] Kang Xia. Exploration on the scaffolding instruction mode in higher vocational oral English teaching guided by the constructivism theory. Bioresource Technology, 2015, 191(1):146-156.

[6] Xiangmin L . Characteristics and rules of college English education based on cognitive process simulation. Cognitive Systems Research, 2019, 57(OCT.):11-19.

[7] Yang, N. D. Developing a web-based learning portfolio system for English teaching and assessment. ieee transactions on power delivery, 2006, 7:2(2):729-734.

[8] Huang Jianbin, Shao Yongzhen. the Way out of College English Teaching Reform. Foreign Language Circles, 1998 (04): 20-22

[9] Shen J , Joynt G M , Critchley L A H , et al. Survey of current status of intensive care teaching in English-speaking medical schools.. Critical Care Medicine, 2003, 31(1):293.

[10] Zheng Xinmin, Jiang Qunying. a Study on "teacher Belief" in College English Teaching Reform. Foreign Language Circles, 2005 (6): 16-22 